\title{
Ant Colony Optimization for Traveling Tourism Problem on Timor Island East Nusa Tenggara
}

\author{
${ }^{1}$ Yampi R. Kaesmetan, ${ }^{2}$ Marlinda Vasty Overbeek \\ ${ }^{1}$ Study Program Informatics Technique, STIKOM Uyelindo Kupang \\ ${ }^{2}$ Study Program Informatics, Faculty of Techniques and Informatics, Universitas Multimedia Nusantara Tangerang \\ Email: 1kaesmetanyampi@gmail.com, ${ }^{2}$ marlinda.vasty@umn.ac.id
}

\begin{tabular}{l}
\hline \hline Article Info \\
\hline Article history: \\
Received February $17^{\text {th }}, 2020$ \\
Revised February $20^{\text {th }}, 2020$ \\
Accepted March $14^{\text {th }}, 2020$ \\
\hline Keyword: \\
Ant Colony Optimization \\
Optimization \\
Shorthest Path \\
Traveling Tourism Problem \\
\end{tabular}

\begin{abstract}
Timor island consists of five districts and one city, namely Kupang District, South Central Timor District, North Central Timor, Belu District, Malaka District, and Kupang City. On the Timor island, it has natural tourist destinations, culinary tours, cultural and historical attractions most on the island of Timor. The Ant Colony Optimization (ACO) Algorithm is very unique compared to the other nearby search algorithm, this algorithm adopted because of Ant Colony who were looking for food from the nest to food sources by leaving a footprint called Pheromone. Mapping system algorithm using ant, tourist sites can show the shortest route between two points is desired. Ants algorithm proved to be applied in determining the optimum route, but still has the disadvantage of dependence on the parameter value is not maximized. From the test results based on parameters of the cycle and the number of ants affects the simulation time, for ant algorithm parameters. From the test results based on the parameters, $\alpha$ and $\beta$ affects, number of node, the simulation time and the shortest distance varying toward the destination even if the starting location and ending on the same location. From the test result, the simulation time is obtained from number of ants (varying from 30 to 150 ants) and the number of cyles (20 to 300 cycles) is 0.765712 to 39.3943 seconds. While, the test result using number of nodes, it does not affect the execution time, because the system feedback simulation time is less than 2 seconds. The test result using parameter $\alpha, \beta, \rho$ not really affected to with execution time because the simulation time not given a vary different time execute.
\end{abstract}

Copyright (C) 2020 Puzzle Research Data Technology

\author{
Corresponding Author: \\ Yampi R. Kaesmetan, \\ Study Program Informatics Technique, STIKOM Uyelindo Kupang \\ Jl. Perintis Kemerdekaan I, Kayu Putih, Oebobo, Kota Kupang, NTT \\ Email: kaesmetanyampi@gmail.com
}

DOI: http://dx.doi.org/10.24014/ijaidm.v3i1.9274

\section{PENDAHULUAN}

Pariwisata merupakan suatu kegiatan untuk melakukan perjalanan dengan tujuan mendapatkan kenikmatan, mencari kepuasan mengetahui sesuatu, memperbaiki kesehatan, menikmati olahraga atau istirahat, menunaikan ibadah, maupun berziarah. Di Indonesia memiliki banyak tempat untuk berwisata, baik yang sudah terkenal maupun yang belum terkenal oleh masyarakat pada umumnya, tercatat sudah sebanyak 962 tempat wisata yang ada di Indonesia [22]. Salah satu daerah yang menjadi destinasi wisata dalam lima tahun terakhir ini adalah Provinsi Nusa Tenggara Timur. Dari catatan terakhir kunjungan wisatawan di provinsi Nusa Tenggara Timur, pada tahun 2017 jumlah wisatawan domestik atau wisatawan nusantara adalah sebanyak 523 083 orang dan wisatawan mancanegara adalah sebanyak 94455 orang. Dari pencatatan tersebut didapat peningkatan yang cukup signifikan, yaitu untuk mancanegara, peningkatan terjadi sebesar $8.3 \%$ dari tahun sebelumnya, sedangkan untuk wisatawan domestik memiliki peningkatan sebesar 4.67\% [1,2]. Peningkatan tersebut sangat signifikan karena di Nusa Tenggara Timur banyak wisata alam, wisata buatan dan wisata

Journal homepage: http://ejournal.uin-suska.ac.id/index.php/IJAIDM/index 
kuliner yang sedang berkembang sehingga banyak dilihat oleh para investor, baik dari pihak pemerintah maupun pihak swasta[26].

Pulau Timor yang merupakan salah satu pulau yang ada di Nusa Tenggara Timur terdiri dari lima kabupaten, yaitu Kabupaten Kupang, Kabupaten Timor Tengah Selatan, Kabupaten Malaka, Kabupaten Belu dan Kabupaten Timor Tengah Utara, serta memiliki satu kota madya yaitu Kota Kupang[23]. Di pulau Timor ini, paling banyak memiliki daerah destinasi wisata di bandingkan dengan daerah lain di Nusa Tenggara Timur, yaitu sebanyak 55 destinasi wisata baik wisata alam, buatan maupun kuliner[24].

Meskipun demikian, para wisatawan masih kebingungan untuk daerah wisata yang ada di Nusa Tenggara Timur khususnya di Pulau Timor. Kendala utama di Pulau Timor adalah jarak antara satu lokasi ke lokasi lain, transportasi, akomodasi, dan kurangnya informasi yang tersedia, terutama bagi tempat wisata yang belum terekspos walaupun secara keindahan tidak kalah dengan destinasi wisata yang sudah terkenal. Berdasarkan hal tersebut maka pada penelitian ini kami mengangkat tentang kurangnya informasi tentang tempat wisata dan tidak adanya sistem yang memberikan rekomendasi tempat wisata berdasarkan jarak masingmasing lokasi wisata yang ada di kabupaten dan kota madya di Pulau Timor.

Algoritma untuk pencarian jalur terdekat sudah banyak yang dikembangkan. Salah satu algoritma tersebut adalah Ant Colony Optimization (ACO) yang dikembangkan oleh Dorigo et al [3,4]. Algoritma ini merupakan algoritma yang sangat unik dibandingkan dengan algoritma pencarian jarak terdekat lainnya karena algoritma ini diadopsi dari koloni semut yang sedang mencari makanan dari sarang menuju sumber makanan dengan meninggalkan suatu jejak kaki yang disebut dengan feromon [5-7].

Awalnya algoritma ACO digunakan sebagai algoritma pencarian jalur terpendek untuk permasalahan Traveling Salesman Problem (TSP) [8,9]. Selanjutnya algoritma ini digunakan untuk beberapa penyelesaian masalah optimasi, misalnya dalam optimasi untuk bilangan diskrit [10], perkembangan ACO untuk masalah TSP dengan MAX-MIN Ant System (MMAS) [11, 12], peningkatan hasil citra dari Synthetic Aperture Radar (SAR) yang dihasilkan oleh deteksi tepi Sobel dan Prewitt [13], dalam bidang robotika [14], penanganan kolisi pada mesin Question - Answering [15], optimasi jalur listrik [16,17], optimasi transit untuk jalur kereta [18], dan vehicle routing problem [19-21].

Dari penelitian tersebut maka pada penelitian ini kami menggunakan ACO untuk melakukan optimasi jalur terpendek untuk Traveling Tourism Problem di Pulau Timor Nusa Tenggara Timur dengan hanya melihat pada jarak dari lokasi wisata tersebut. Pemanfaatan Geographic Information System juga digunakan dalam penelitian ini untuk mempermudah para wisatawan untuk melihat jalur terpendek destinasi pariwisata yang hendak dikunjungi. Sedangkan untuk banyaknya lokasi wisata di Pulau Timor, diinisialisasikan sebagai node sebanyak 20 lokasi wisata yang ada di Pulau Timor. Lokasi atau destinasi wisata tersebut adalah wisata alam, wisata kuliner dan wisata buatan.

\section{METODE PENELITIAN}

Kerangka kerja pada penelitian ini merupakan langkah-langkah yang akan dilakukan dalam melakukan penyelesaian masalah yang akan dibahas. Adapun detail kerja penelitian tahapan demi tahapannya dapat dilihat pada Gambar 1.

Detail kerja dari metodologi tersebut adalah sebagai berikut :

a. Pengumpulan data

Pada tahap ini dilakukan pengumpulan semua data atau informasi yang berkaitan dengan penelitian. Pengumpulan data ini dilakukan dengan cara observasi, wawancara, studi pustaka dan data lain yang mendukung penelitian ini mengenai data proses pencarian jalur terpendek. Untuk lokasi wisata, dilakukan observasi juga secara langsung dan mendapatkan 20 lokasi wisata yang diinisalisasikan sebagai node pada data tersebut dan juga jarak diinisialisasikan dalam kilometer.

b. Implementasi ACO

Pada tahap ini dilakukan sebagian perhitungan manual terhadap pemetaan lokasi wisata dengan menggunakan algoritma ACO untuk menentukan permasalahan jalur terpendek dengan desain ataupun tampilan antar muka sistem pencarian jalur terpendek di Pulau Timor dengan ACO dengan menggunakan perangkat lunak Matlab R2018a [25]. untuk lengkah kerja ACO dalam implementasi pencarian jalur terpendek pada permasalahan pencarian jalur terpendek di Pulau Timor, di gambarkan pada Gambar 2. 


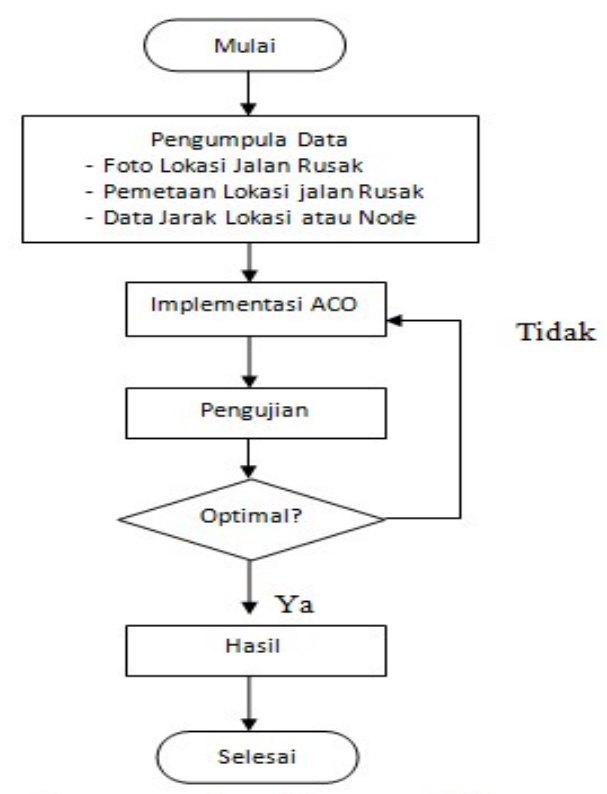

Gambar 1. Langkah kerja Traveling Tourism Problem di Pulau Timor dengan ACO

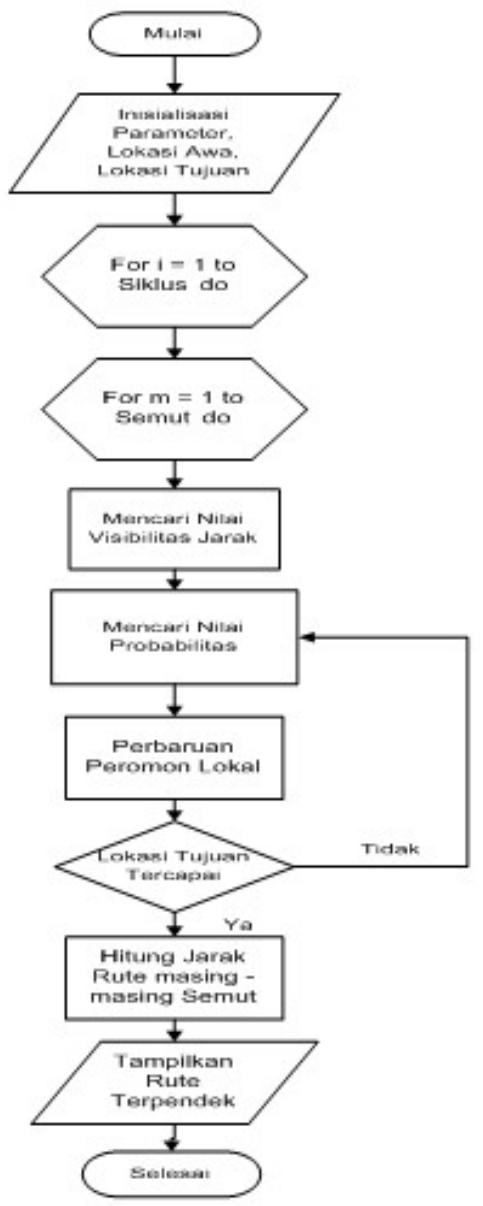

Gambar 2. Diagram alir Ant Colony Optimization 
Langkah kerja dari algoritma ACO [3], dimulai dari menginisialisasi $m$ semut yang merupakan solusi dari tiap iterasi dan digunakan untuk melakukan update feromon. Nilai dari feromon awal $\tau_{i j}$, dengan $i$ dan $j$ adalah edge antara dua titik. Cara melakukan updating adalah dengan menggunakan persamaan (1)

$$
\tau_{i j}=(1-\rho) \cdot \tau_{i j}+\sum_{k=1}^{m} \Delta \tau_{i j}^{k}
$$

Dimana $\rho$ adalah laju evaporasi dari feromon, $m$ adalah banyak semut dan $\Delta \tau_{i j}^{k}$ adalah kuantitas feromon yang pada $e d g e(i, j)$ dari semut ke- $k$ pada persamaan (2).

$$
\Delta \tau_{i j}^{k}=\left\{\begin{array}{rr}
\frac{Q}{L_{k}} \text { if edge }(i, j) \text { in the ant } k \\
0 \quad \text { Otherwise }
\end{array}\right.
$$

Dimana $Q$ adalah konstanta, $L_{k}$ adalah panjang dari jalur yang dibangun oleh semut ke- $k$. Selama proses, semut akan memilih titik selanjutnya dengan cara stokhastik. Probabilitas untuk pergerakan semut dari satu titik $i$ ke titik $j$ dihitung dengan persamaan (3).

$$
p_{i j}^{k}=\left\{\frac{\tau_{i j}^{\alpha} \cdot \eta_{i j}^{\beta}}{\sum_{\left.c_{i l \epsilon N(s} p\right)} \tau_{i j}^{\alpha} \cdot \eta_{i j}^{\beta}}\right.
$$

Dimana $\mathrm{N}\left(s^{p}\right)$,adalah set dari elemen yang cocok, yaitu edge $(i, l)$ dengan parameter $l$ adalah titik yang belum dikunjungi oleh semut ke- $k$. Parameter $\alpha$ dan $\beta$ berhubungan dengan nilai antara feromon dan informasi heuristik yang diberikan oleh persamaan (4), dengan $\alpha$ dan $\beta$ merepresentasikan pengendali intensitas jejak semut dan pengendali visibilitas.

$$
\eta_{i j}=1 / d_{i j}
$$

Dimana parameter $d_{i j}$ menunjukkan jarak antara titik $i$ dan $j$.

c. Pengujian sistem

Pada tahap ini dilakukan pengujian terhadap kinerja sistem dan kebenaran hasil algoritma ACO berdasarkan jumlah node, banyak siklus, banyak semut, parameter alpha $(\alpha)$, beta $(\beta)$, dan evaporasi feromon $(\rho)$

d. Hasil

Hasil dari penelitian ini adalah didapatkan jalur terpendek untuk lokasi wisata atau destinasi wisata yang ada di Pulau Timor dengan ACO hanya berdasarkan jarak.

\section{HASIL DAN ANALISA}

\subsection{Akuisisi Data}

Hasil eksprerimental pada penelitian ini dimulai dari memasukkan node atau destinasi wisata yang ada di Pulau Timor sebanyak 20 lokasi wisata. Adapun lokasi yang digunakan pada penelitian ini ditampilkan pada peta pada Gambar 3.

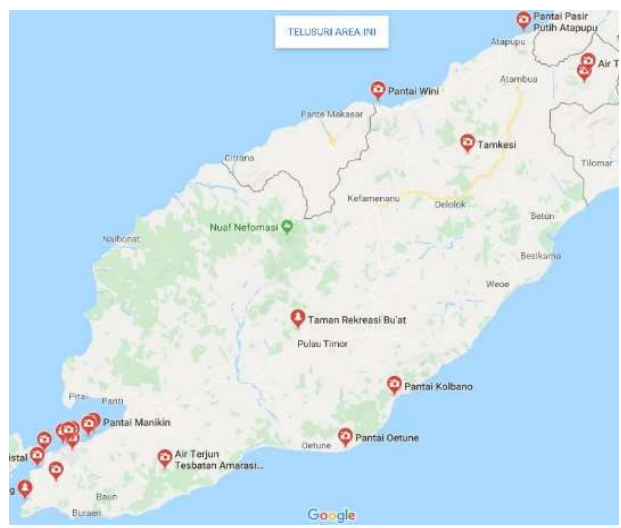

Gambar 3 Peta 20 lokasi wisata di Pulau Timor

Ant Colony Optimization for Traveling Tourism... (Kaesmetan et al) 
Adapun inisialisasi parameter awal pada penelitian ini adalah jejak feromon awal $\tau_{i j}=0.01, \alpha$ dan $\beta$ masing-masing bernilai 1 , evaporasi $\rho$ adalah 0.5 , banyak semut sebanyak 1 , dan siklus $\left(N c_{\max }\right)=1$.

\subsection{Perhitungan Jarak Node dan Visibilitas Jarak antar Node}

Dari hasil perhitungan awal, maka didapat jarak antar node (dalam km), yang ditampilkan pada Tabel 1, sedangkan visibilitas jarak antar node $\eta_{i j}$ dapat dilihat pada Tabel 2.

Tabel 1. Data Jarak Node (km)

\begin{tabular}{cccccccc}
\hline Node $(\mathrm{km})$ & 1 & 2 & 3 & 4 & 20 & 55 & 56 \\
\hline 1 & 0 & 90 & & & & & \\
2 & 90 & 0 & 42 & & & & 150 \\
3 & & 42 & 0 & 140 & & & \\
4 & & & 140 & 0 & & 135 & \\
20 & & & & & 0 & & 75 \\
55 & & & & 135 & & 0 & 150 \\
56 & & 150 & & & 75 & 150 & 0 \\
\hline
\end{tabular}

Tabel 2. Hasil dari $\eta_{i j}=1 / d i j$

\begin{tabular}{cccccccc}
\hline Node $(\mathrm{km})$ & 1 & 2 & 3 & 4 & 20 & 55 & 56 \\
\hline 1 & 0 & 0,0111 & & & & & \\
2 & 0,0111 & 0 & 0,0238 & & & & 0,0066 \\
3 & & 0,0238 & 0 & 0,0071 & & & \\
4 & & & 0,0071 & 0 & & 0,0074 & \\
20 & & & & & 0 & & 0,0133 \\
55 & & & & 0,0074 & & 0 & 0,0066 \\
56 & & 0,0066 & & & 0,0133 & 0,0066 & 0 \\
\hline
\end{tabular}

\subsection{Pengujian Sistem}

a. Pengujian Berdasarkan Jumlah Semut dan Jumlah Siklus

Pengujian ini dilakukan dengan mengubah jumlah siklus dan mengubah jumlah semut dalam satu siklus dan dilakukan pencarian lokasi asal dan lokasi tujuan. Nilai parameter yang digunakan adalah $\alpha=0,3$ nilai $\beta=0,5$ dan nilai $\rho=0,4$. Hasil pengujian dilihat pada Tabel 3 .

Tabel 3. Pengujian berdasarkan banyak siklus dan banyak semut

\begin{tabular}{ccccc}
\hline No & Banyak semut & Cycle & Shortest path $(\mathrm{km})$ & Sim. time $(\mathrm{s})$ \\
\hline 1 & 30 & 20 & 245.23 & 0.765712 \\
2 & 40 & 70 & 233.81 & 2.71222 \\
3 & 90 & 60 & 233.81 & 4.98122 \\
4 & 80 & 180 & 233.81 & 12.8264 \\
5 & 100 & 200 & 233.81 & 18.0314 \\
6 & 135 & 250 & 233.81 & 28.8998 \\
7 & 150 & 300 & 233.81 & 39.3943 \\
\hline
\end{tabular}

b. Pengujian Berdasarkan Parameter $\alpha, \beta, \rho$

Pengujian ini dilakukan dengan mengubah parameter $\alpha, \beta, \rho$ kemudian diuji dengan pencarian antara lokasi asal dan lokasi tujuan yang tetap yaitu dari titik lokasi pertama ke lokasi ke 19. Sedangkan untuk jumlah semut $=50$ dan jumlah siklus $=135$. Hasil pengujian dapat dilihat pada Tabel 4 .

Tabel 4. Pengujian Berdasarkan Parameter $(\alpha, \beta, \rho)$

\begin{tabular}{cccccc}
\hline No & $\alpha$ & $\beta$ & $\rho$ & Shortest path $(\mathrm{km})$ & Sim. Time $(\mathrm{s})$ \\
\hline 1 & 0.1 & 0.3 & 0.2 & 226.69 & 8.63375 \\
2 & 0.3 & 0.5 & 0.4 & 226.69 & 6.01411 \\
3 & 0.5 & 0.7 & 0.6 & 226.69 & 5.84098 \\
4 & 0.8 & 0.9 & 0.74 & 233.06 & 8.14804 \\
5 & 1 & 1 & 0.8 & 302.75 & 3.41041 \\
6 & 1.4 & 1.5 & 0.93 & 252.57 & 8.20754 \\
7 & 2 & 2 & 1 & 251.11 & 2.6348 \\
\hline
\end{tabular}

c. Pengujian Berdasarkan Jumlah Node

Pengujian berdasarkan jumlah node membandingkan kecepatan pencarian rute terpendek berdasarkan total jarak dan waktu dengan banyak node yang dilalui. Nilai parameter yang digunakan adalah $\tau_{0}$ $=0.01, \alpha=0.1, \beta=0.5, \rho=0.5$, banyak semut $=27$ dan nilai siklus $\left(N c_{\max }\right)=50$. Hasil pengujian ditampilkan pada Tabel 5 .

IJAIDM Vol. 3, No. 1, March 2020: $28-35$ 
Tabel 5. Pengujian Berdasarkan Node

\begin{tabular}{ccccccc}
\hline No & $\begin{array}{c}\text { Lokasi } \\
\text { Awal }\end{array}$ & $\begin{array}{c}\text { Lokasi } \\
\text { Tujuan }\end{array}$ & $\begin{array}{c}\text { Jumlah } \\
\text { Node }\end{array}$ & Rute & $\begin{array}{c}\text { Jarak } \\
(\mathrm{km})\end{array}$ & $\begin{array}{c}\text { Sim. Time } \\
(\mathrm{s})\end{array}$ \\
\hline 1 & 1 & 16 & 10 & $1-2-21-26-27-28-31-34-33-16$ & 0.872 & 1.79379 \\
2 & 3 & 7 & 9 & $3-2-56-20-6-59-23-24-7$ & 0.717 & 1.44949 \\
3 & 19 & 16 & 10 & $19-43-45-61-52-53-15-32-30-16$ & 0.855 & 1.845048 \\
4 & 14 & 4 & 13 & $17-36-18-53-7-24-23-59-6-20-56-55-4$ & 1.254 & 1.72523 \\
5 & 5 & 10 & 10 & $5-57-58-59-23-24-25-8-9-10$ & 0.705 & 1.49254 \\
\hline
\end{tabular}

\subsection{Hasil Implementasi}

Adapun hasil implementasi dari sistem pencarian rute lokasi dengan ACO ditunjukkan pada Gambar 4. Antar muka dari sistem dikembangkan dengan menggunakan perangkat lunak Matlab R2018a.

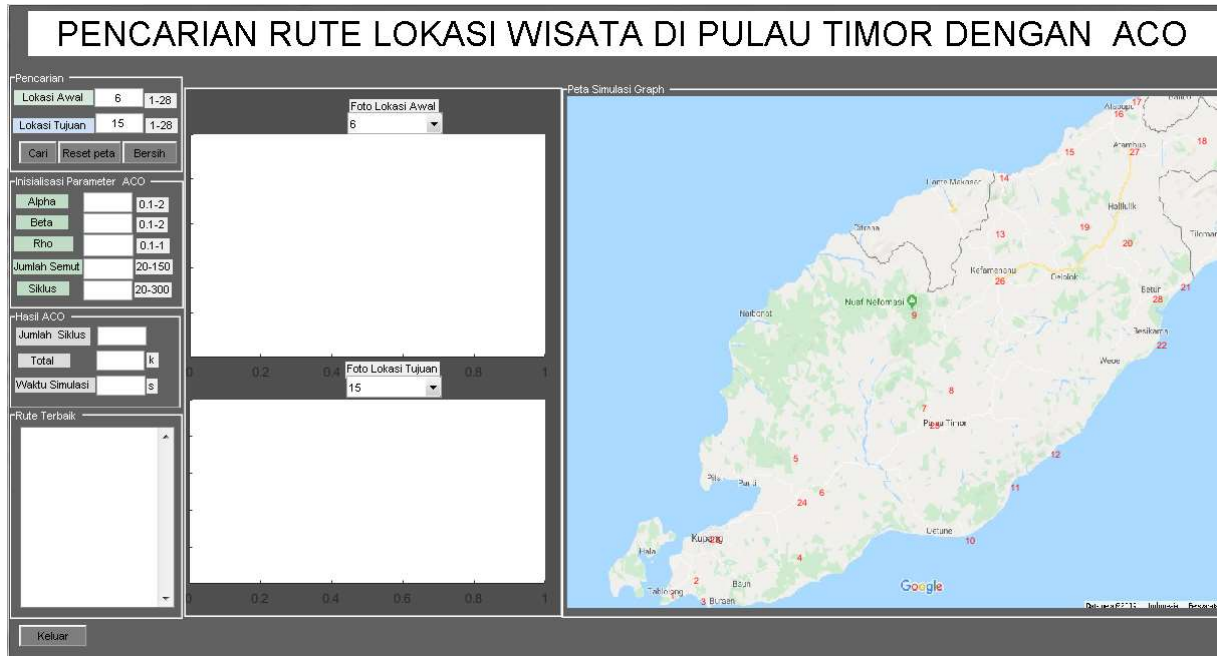

Gambar 4 Tampilan antar muka pencarian rute lokasi wisata di Pulau Timor dengan ACO

\section{SIMPULAN}

Pencarian jalur terpendek dengan ACO untuk Traveling Tourism Problem di Pulau Timor sudah diimplementasikan dengan baik. Hal ini dilihat dari hasil pengujian, bahwa semakin tinggi jumlah semut dan jumlah siklus, maka akan menghasilkan rute yang terpendek walaupun waktu simulasi semakin lama. Selain itu juga diketahui bahwa penentuan parameter $\alpha, \beta, \rho$ sangat mempengaruhi hasil rute terpendek dan waktu simulasi, semakin rendah penentuan nilai parameter maka jarak yang dihasilkan yaitu rute yang terpendek walapun waktu simuliasi sistem yang dihasilkan lumayan lambat sedangan semakin tinggi penentuan nilai parameter maka hasil rute belum optimum tetapi memiliki waktu simuliasi yang cepat. Untuk hasil pengujian berdasarkan jumlah node, terlihat bahwa walaupun semakin banyak node yang dilewati, waktu yang digunakan untuk mencari node tujuan ternyata tidak terlalu berpengaruh. Hal tersebut menunjukkan bahwa ACO cocok digunakan untuk pencarian dengan vertex persimpangan dalam jumlah yang banyak.

\section{REFERENCES}

[1]. [BPS] Badan Pusat Statistik Provinsi NTT. 2019. Jumlah Wisatawan Domestik Menurut Kabupaten Kota di Provinsi NTT tahun 2010 - 2017. [internet][download : 2019 July 05]. Website : https://ntt.bps.go.id/dynamictable/2018/09/06/785/jumlah-wisatawan-domestikmenurut-kabupatenkota-di-provinsi-nusa-tenggara-timur-2010-2017.html

[2]. [BPS] Badan Pusat Statistik Provinsi NTT. 2019. Jumlah Wisatawan Mancanegara Menurut Kabupaten Kota di Provinsi NTT tahun 2006 - 2017. [internet][download : 2019 July 05]. Website : https://ntt.bps.go.id/dynamictable/2015/03/17/54/jumlah-wisatawan-mancanegara-menurutkabupaten-kota-di-provinsi-nusa-tenggara-timur-2006-2017.html

[3]. Dorigo M, Maniezzo V and Colorni A. "Distributed optimization by ant colonies" Proceedings of the 1st European COnference on Artificial Life, pp.134-142, 1991.

[4]. M. Dorigo, V. Maniezzo and A. Colorni, "Ant System : Optimization by an colony cooperating Agents," IEEE Transactions on Systems, Man, and Cybernetics, Part B, vol.26, no.2, pp.29-41, 1996

[5]. X. Xue, X. Cheng, B. Xu, H. Wang and C. Jiang, "The basic principle and application of ant colony optimization algorithm," 2010 International Conference on Artificial Intelligence and Education (ICAIE), Hangzhou, 2010, pp. 358-360. 
[6]. Y. Pei, W. Wang and S. Zhang, "Basic Ant Colony Optimization," 2012 International Conference on Computer Science and Electronics Engineering, Hangzhou, 2012, pp. 665-667.

[7]. M. Dorigo, M. Birattari and T. Stutzle, "Ant colony optimization," in IEEE Computational Intelligence Magazine, vol. 1, no. 4, pp. 28-39, Nov. 2006.

[8]. M Dorigo and L.M. Gambardella. "Ant Colony System : A cooperative learning approach to the traveling salesman problem," IEEE Transaction on Evolutionary Computation, vol.1, no.1, pp.5666,1997

[9]. M. Dorigo and L.M. Gambardella, "Ant colonies for the traveling salesman problem," BioSystems, vol.43, no.2, pp.77-81, 1997.

[10]. M. Dorigo, G. Di Caro and L.M. Gambardella, "Ant algorithms for discrete optimization," Artificial Life, vol.5, no.2, pp.137-172, 1999.

[11]. T. Stutzle and H. Hoos, "MAX-MIN Ant System and local search for the traveling salesman problem," Proceedings of 1997 IEEE International Conference on Evolutionary Computation (ICEC '97), Indianapolis, IN, USA, 1997, pp. 309-314.

[12]. Zhaojun Zhang and Zuren Feng, "A novel Max-Min ant system algorithm for traveling salesman problem," 2009 IEEE International Conference on Intelligent Computing and Intelligent Systems, Shanghai, 2009, pp. 508-511.

[13]. L. Li and J. Wang, "SAR image ship detection based on Ant Colony Optimization," 2012 th International Congress on Image and Signal Processing, Chongqing, 2012, pp. 1100-1103.

[14]. X. Li, Z. Liu and Y. Zhang, "A Novel Improved Ant Colony Algorithm for Multi-Robot Task Allocation," 2018 IEEE 4th Information Technology and Mechatronics Engineering Conference (ITOEC), Chongqing, China, 2018, pp. 1629-1633.

[15]. S. Di, P. He and H. Li, "Agent Coalition Formation of Chinese Question Answering System Based on Improved Ant Colony Algorithm," 2010 International Conference on e-Education, e-Business, eManagement and e-Learning, Sanya, 2010, pp. 98-101.

[16]. Xian-Yi Ye, Xiao-Rong Cheng, Lu-Ming Liu and Qi-Yuan Feng, "Research of the Best Repair Path Based on an Improved Ant Colony Algorithm in Power Distribution Network," 2005 IEEE/PES Transmission \& Distribution Conference \& Exposition: Asia and Pacific, Dalian, 2005, pp. 1-5.

[17]. G. Weixin, L. Xianjue, T. Nan and M. Xiangyang, "Improved Ant Algorithm Combined with Ecological Theory for Urban Power System Planning," 2009 International Conference on Artificial Intelligence and Computational Intelligence, Shanghai, 2009, pp. 229-233.

[18]. L. Sheng and Y. Xiaoming, "The Design and Implementation of Urban Rail Transit Optimal Transfer System Based on Improved Ant Colony Algorithm," 2012 Second International Conference on Business Computing and Global Informatization, Shanghai, 2012, pp. 770-773.

[19]. Hiroaki Ono and Yasuchika Mori, "The optimal design of the vehicle routing problem with time windows by ant colony system," SICE Annual Conference 2007, Takamatsu, 2007, pp. 1325-1329.

[20]. G. Yancheng, H. Ronggui, Y. Xirui, S. Hongxing and L. Chang, "Improved ant colony algorithm for vehicle scheduling problems of military logistics distribution," 2010 International Conference on Logistics Systems and Intelligent Management (ICLSIM), Harbin, 2010, pp. 669-673.

[21]. X. Han and X. Zhang, "School Bus Route Optimization Based on Improved Ant Colony Algorithm," 2019 4th International Conference on Electromechanical Control Technology and Transportation (ICECTT), Guilin, China, 2019, pp. 312-316

[22]. Pusat Data Indonesia.2020.Pariwisata Indonesia. [internet][download : 2020 Maret 05]. Website : https://data.go.id/dataset?tags=wisata

[23]. Pemerintah Provinsi NTT. 2020. Kabupaten dan Kota se-NTT. [internet][download : 2020 Maret 05]. Website : https://nttprov.go.id/ntt/kabupaten-dan-kota-se-ntt/

[24]. Dinas Pariwisata Provinsi NTT. 2020. Pariwisata NTT. [internet][download : 2020 Maret 05]. Website : http://nttprov.go.id/2018/index.php/pariwisata

[25]. MatLab. 2018. Matrix Laboratory. Website : https://www.mathworks.com/products/matlab.html

[26]. Overbeek MV; Naatonis RN.2019. Sistem Rekomendasi Destinasi Wisata di Kota Kupang dengan Metode Weighted Product. Jurnal HOAQ STIKOM Uyelindo Kupang vol 9

IJAIDM Vol. 3, No. 1, March 2020: 28-35 


\section{BIBLIOGRAFI PENULIS}

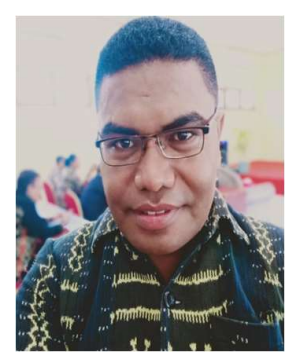

Yampi R. Kaesmetan, S.Kom, M.Kom, sekarang bekerja di STIKOM Uyelindo Kupang sebagai Dosen di Program Studi Teknik Informatika.

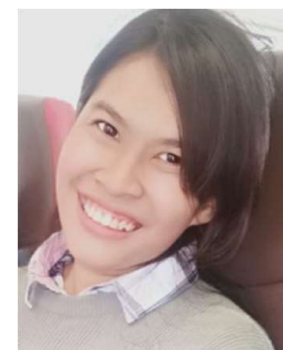

Marlinda Vasty Overbeek, S.Kom, M.Kom, adalah seorang Dosen. Karir awal sebagai dosen di STIKOM Uyelindo Kupang pada program studi Teknik Informatika. Sekarang berpindah ke Tangerang, Banten dan berkarir pada Universitas Multimedia Nusantara sebagai dosen. 